\title{
МОРФОФУНКЦИОНАЛЬНЫЕ ОСОБЕННОСТИ СЛИЗИСТОЙ ОБОЛОЧКИ ПОЛОСТИ РТА ЛИЦ, СТРАДАЮЩИХ ХРОНИЧЕСКИМИ ВОСПАЛИТЕЛЬНЫМИ ЗАБОЛЕВАНИЯМИ КИШЕЧНИКА
}

\author{
(С Тытюк С.Ю. , Пихур О.Л. ${ }^{2}$, Тишков Д.С. ${ }^{3}$, Иорданишвили А.К. ${ }^{1}$ \\ ${ }^{1}$ Военно-медицинская академия им. С.М. Кирова, Санкт-Петербург; ${ }^{2}$ Северо-Западный \\ государственный медицинский университет им. И.И. Мечникова, Санкт-Петербург; \\ ${ }^{3}$ Курский государственный медицинский университет, Курск \\ E-mail: pol0012@mail.ru
}

\begin{abstract}
В результате проведенных исследований с помощью методов контактной компьютерной биомикроскопии и кроссполяризационной оптической когерентной томографии проведена оценка микроциркуляции, воспалительного и фиброзирующего процесса в слизистой оболочке послости рта у больных, страдающих хроническими воспалительными заболеваниями кишечника (болезнь Крона и хронический неспецифический язвенный колит), определена частота встречаемости отдельных морфологических признаков и выявлены различия между группами обследованных лиц. Установлено увеличение диаметра артериолярной и венулярной частей капилляров, деформация микрососудов, замутненность и смазанность микрососудистого рисунка слизистой оболочки полости рта больных с хроническими воспалительными заболеваниями кишечника, которые свидетельствуют о развитии ангиопатии, степень выраженности которой у пациентов с болезнью Крона больше по сравнению лицами, страдающими хроническим неспецифическим язвенным колитом. Микроструктурные изменения слизистой оболочки полости рта пациентов с болезнью Крона, при сравнении с лицами контрольной группы и с хроническим неспецифическим язвенным колитом характеризуются избыточным накоплением коллагена в соединительнотканной строме.
\end{abstract}

Ключевые слова: слизистая оболочка полости рта, болезнь Крона, хронический неспецифический язвенный колит.

\section{MORPHOLOGICAL AND FUNCTIONAL FEATURES OF ORAL MUCOSA IN PERSONS WITH CHRONIC INFLAMMATORY BOWEL DISEASES Tityuk S.Yu. ${ }^{\prime}$, Pikhur O.L. ${ }^{2}$, Tishkov D.S. ${ }^{3}$, Iordanishvili A.K. ${ }^{l}$ \\ ${ }^{1}$ S.M. Kirov Millitary Medical Academy, St. Petersburg;}

${ }^{2}$ I.I. Mechnikov North-West Medical University, St. Petersburg; ${ }^{3}$ Kursk State Medical University, Kursk

The research conducted by the methods of contact computer biomicroscopy and cross-polarization optical coherent tomography allowed to assess the microcirculation, and inflammatory and fibrosing process in the oral mucosa in patients with chronic inflammatory bowel diseases (Crohn's disease and chronic nonspecific ulcerative colitis), to determine the frequency of certain morphological features and to reveal the differences between the individuals examined. The increase in the arteriolar and venular diameters of capillaries, deformation, haziness, and blurriness of microvascular picture of the oral mucosa in patients with chronic inflammatory bowel diseases showed the angiopathy development, being higher in patients with Crohn's disease as compared to individuals suffering from chronic nonspecific ulcerative colitis. Microstructural changes of the oral cavity mucosa in patients with Crohn's disease in comparison with the control groups and individuals with chronic ulcerative colitis are characterized by an excessive accumulation of collagen in the connective tissue stroma.

Keywords: mucosa of oral cavity, Crohn's disease, chronic nonspecific ulcerative colitis.

Известна тесная взаимосвязь между заболеваниями органов и тканей полости рта и патологией желудочно-кишечного тракта (ЖКТ) $[6,9,12,13]$. Ряд авторов указывает не только на анатомическую, но и функциональную связь различных отделов пищеварительного тракта, включая полость рта, в рамках единой структурно-функциональной системы, определяющей взаимовлияние и взаимозависимость этих отделов [7, 10, 22]. Очевидно, этим объясняется высокая частота и разнообразная клиническая картина патологических изменений в полости рта при заболеваниях ЖКТ.

В последние десятилетия в патологии желудочно-кишечного тракта наблюдается рост уровня хронических воспалительных заболеваний кишечника (ХВЗК), к которым относят болезнь Крона (БК) и хронический неспецифический язвенный колит (ХНЯК), отличающиеся тяжестью поражений и развитием опасных осложнений, при этом этиология и патогенез БК и ХНЯК полностью не выяснены $[1-5,11]$.

Основанием для настоящего исследования послужили данные отечественных и зарубежных авторов о высокой частоте стоматологических заболеваний у лиц, страдающих ХВЗК $[8,15,18$, 24]. В литературных источниках отмечаются изменения слизистой оболочки полости рта (СОПР), пародонта, твердых тканей зубов у пациентов с болезнью Крона и хроническим 
неспецифическим язвенным колитом [14, 20, 23$]$. Однако малоизученными остаются вопросы морфофункциональных изменений в СОПР у больных, страдающих ХВЗК, нет ясности в отличиях проявлений стоматологической патологии у лиц, страдающих БК и ХНЯК.

Цель исследования: изучить морфофункциональные особенности слизистой оболочки полости у взрослых людей, страдающих хроническими воспалительными заболеваниями кишечника, с применением современных неинвазивных методов клинического исследования.

\section{МАТЕРИАЛЫ И МЕТОДЫ ИССЛЕДОВАНИЯ}

Проведено обследование 64 стоматологических больных с хроническими воспалительными заболеваниями кишечника в возрасте от 20 до 69 лет. В соответствии с основным соматическим заболеванием сформированы две группы обследуемых лиц: I группа - с болезнью Крона (34 человека в возрасте от 20 до 63 лет) и II группа - с хроническим неспецифическим язвенным колитом (30 человек в возрасте от 22 до 69 лет). Контрольная группа практически здоровых лиц составляла 20 человек в возрасте от 19 до 72 лет. При исследовании слизистой оболочки полости рта обследованных лиц применены методы контактной компьютерной биомикроскопии (ККБ) и кросс-поляризационной оптической когерентной томографии (КП ОКТ) [17].

Изучение микроциркуляции СОПР проводилось при помощи контактного темнопольного люминесцентного микроскопа МЛК-1 (Россия) с глубиной просмотра тканей от 50 до 250 мкм при увеличении от 50 до 400 раз. Для обработки качественных и количественных характеристик микроциркуляторного русла использовалась система, состоящая из микроскопа МЛК-1, цветной аналоговой видеокамеры и персонального компьютера. Данная система позволяет упростить методику витальной биомикроскопии, облегчает морфометрический анализ полученных данных, увеличивает качество изображения микроциркуляторного русла, а также повышает информативность метода.

При оценке микроструктурных изменений тканей слизистой оболочки полости рта использован оптический когерентный томограф «ОКТ 1300-У» (Россия), который демонстрирует два сопряженных изображения: 1) нижнее (в прямой поляризации) - содержит информацию об обратно-рассеивающих свойствах ткани; 2) верхнее (в ортогональной поляризации) кроме характеристик обратного рассеяния дает представление о деполяризующих свойствах коллагена, кератина и других анизотропных структур ткани, что существенно увеличивает клиническую значимость метода оптической когерентной томографии (ОКТ).

Прибор оснащен торцевым эндоскопическим зондом, наружный диаметр которого составляет 2,7 мм. В устройстве используется зондирующее излучение с длиной волны 1300 нм и мощностью 3 мВт. Прибор имеет два канала и одновременно демонстрирует два сопряженных изображения. Каждое КП ОКТ изображение, которое регистрируется в течение 2 секунд, имеет следующие характеристики: 200×512 пикселей, размер 2х2,3 мм, разрешение по глубине 15 мкм в свободном пространстве, продольное разрешение 25 мкм.

Количественная оценка КП ОКТ изображений заключалась в автоматическом вычислении интегрального фактора деполяризации (ИФД) интегрального отношения усредненных по поперечной координате яркостей ОКТ-сигнала в ортогональной поляризации, к такой же величине, рассчитанной для ОКТ-сигнала в исходной поляризации.

При вычислении ИФД учитывался фоновый сигнал:

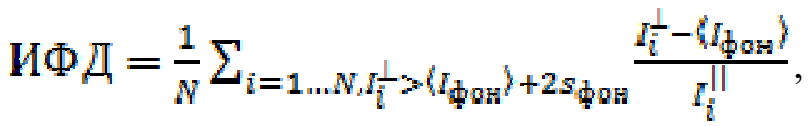

где: $\mathrm{I}_{\mathrm{i}}^{\|}$- яркость ОКТ-сигнала в исходной поляризации в і-ом пикселе после усреднения по поперечной координате;

$\mathrm{I}_{\mathrm{i}}^{\perp}$ - яркость ОКТ-сигнала в ортогональной поляризации в і-ом пикселе после усреднения по поперечной координате;

$\mathrm{N}$ - число пикселей в усредненном по поперечной координате ОКТ-сигнале в ортогональной поляризации, для которых яркость ОКТ-сигнала превышает среднюю величину фонового ОКТ-сигнала $\left\langle\mathrm{I}_{\text {фон }}\right\rangle$ на его удвоенное стандартное отклонение $2 \mathrm{~s}_{\text {фон }}$.

Статистическая обработка данных выполнялась на персональном компьютере с использованием стандартного пакета программ прикладного статистического анализа (Statistica for Windows v. 7.0). Методы описательной статистики включали оценку среднего арифметического, стандартной ошибки среднего значения. Для оценки межгрупповых различий значений признаков, имеющих непрерывное распределение, применяли t-критерий Стьюдента и непараметрический U-критерий ВилкоксонаМанна-Уитни, а при сравнении частотных величин $-\chi^{2}$-критерий Пирсона и точный метод Фишера. Критический уровень достоверности 
нулевой статистической гипотезы принимали равным 0,05 .

\section{РЕЗУЛЬТАТЫ ИССЛЕДОВАНИЯ И ИХ ОБСУЖДЕНИЕ}

Качественный анализ данных, полученных методом контактной компьютерной биомикроскопии, раскрывает характер изменений микроциркуляторного русла слизистой оболочки полости рта больных ХВЗК. В поверхностном слое СОПР в области щеки пациента с БК на глубине около 50 мкм отмечаются расширенные капиллярные петли с замедленным кровотоком, имеющим прерывистый, маятникообразный характер (рис. 1a). Выражена замутненность капилляроскопического фона, свидетельствующая об отеке тканей. В более глубоких (около 250 мкм) слоях слизистой оболочки определяются расширенные венулы, переполненные кровью (рис. 1б). Отмечается размытость, смазанность микрососудистого рисунка. В некоторых венулах наблюдается зернистый кровоток и пристеночное стояние лейкоцитов. Краевое стояние лейкоцитов (маргинация) является одной из стадий лейкоцитарной инфильтрации тканей при воспалении. Отмечаются также расширенные артериолы.
У больных БК в СОПР определяется выраженный отек, развивающийся вследствие увеличения проницаемости гистогематического барьера. Изменения в микрососудах приобретают генерализованный характер. Отмечаются деформации сосудистых стенок, повышенная извитость микрососудов и дупликация капиллярных петель. Выявляются бессосудистые зоны, возникающие из-за локальных выключений капилляров из кровотока. Наиболее характерные изменения микрососудов при БК представлены на рис. 1 в, г. Изменение формы капиллярных петель, усиление их извитости, дупликация, неравномерность просвета микрососудов с варикозными выпячиваниям являются структурными проявлениями атрофических процессов, протекающих на фоне воспаления тканей СОПР. Расширение венулярных отделов капилляров свидетельствует о нарушении тонуса сосудов на уровне микроциркуляторного русла. Признаками изменения нормальной реологии крови является зернистый характер кровотока, агрегаты эритроцитов и пристеночное стояние лейкоцитов. В отдельных капиллярах можно видеть резкое замедление, появление маятникообразности кровотока вплоть до стаза. В периваскулярном пространстве вокруг капилляров определяются точечные геморрагии.

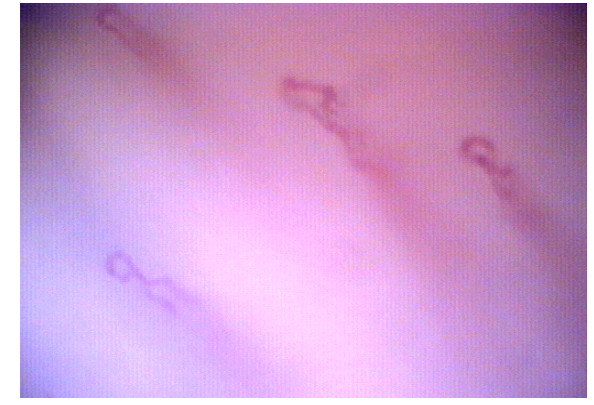

a

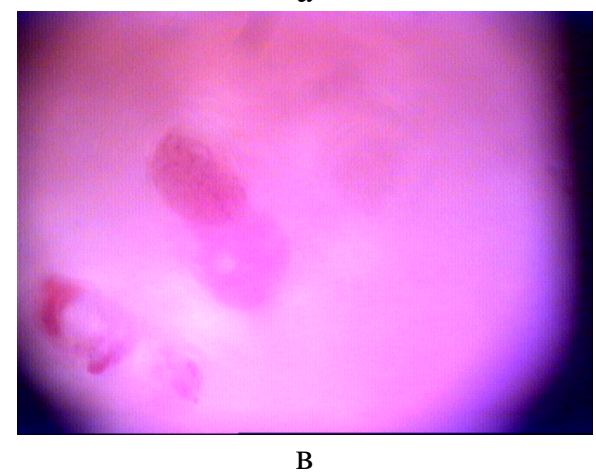

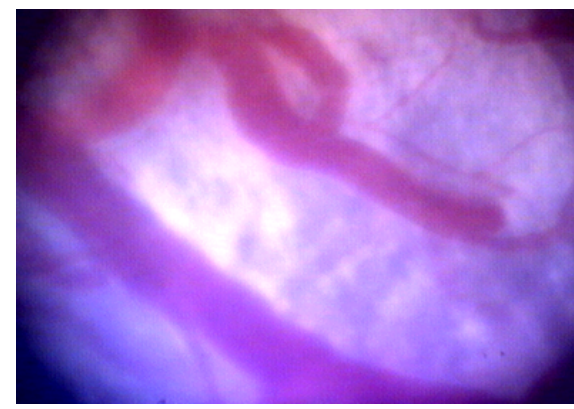

б

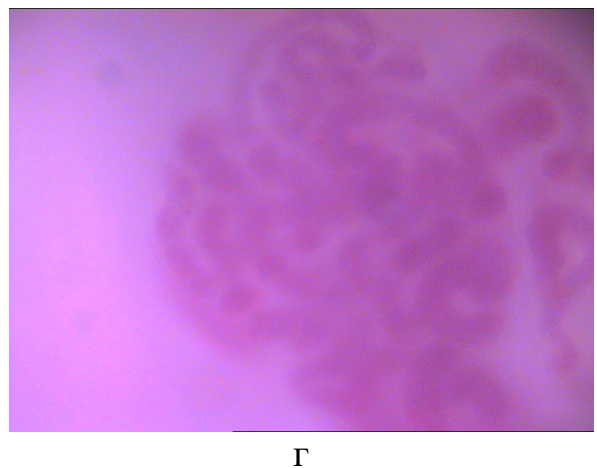

Рис. 1. Пациент с БК, СОПР в области щеки: а - замутненность капилляроскопического фона, расширение капиллярных петель (увел. ×100); б - расширенные венулы, нарушение венозного оттока (увел. $\times 350)$; в - размытость, смазанность микрососудистого рисунка, замутненность капилляроскопического фона, увеличение, дупликация капиллярных петель (увел. $\times 150$ ); г - варикозная деформация сосудов микроциркуляторного русла (увел. ×150). 


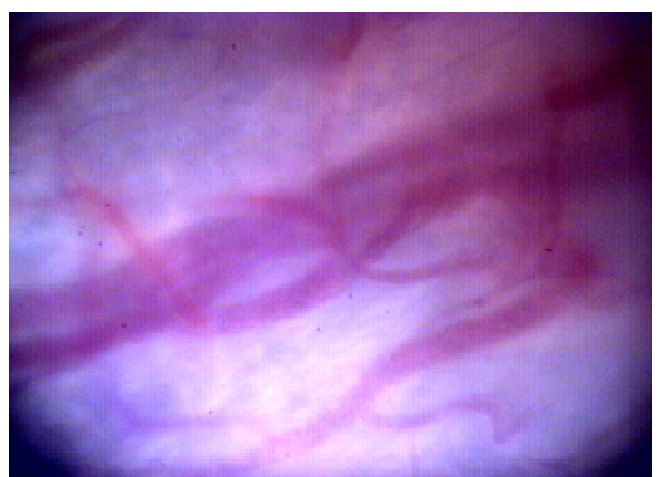

a

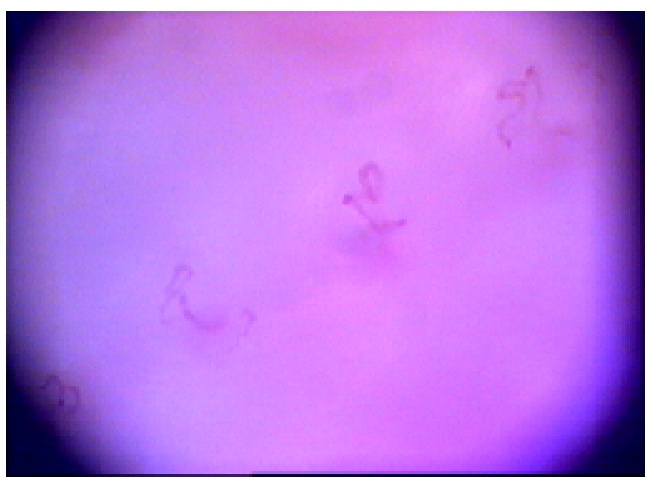

б

Рис. 2. Пациент с ХНЯК, СОПР в области щеки: а - расширенные, увеличенные венулы (увел. ×300);

б- размытость, смазанность микрососудистого рисунка, замутненность капилляроскопического фона, дупликация капиллярных петель (увел. ×100).

Таблица 1

Морфометрические параметры микроциркуляторного русла слизистой оболочки щеки у больных ХВЗК (a), у пациентов с болезнью Крона в сравнении с группой контроля (б), у пациентов с ХНЯК в сравнении с группой контроля (в)

\begin{tabular}{|l|c|c|c|c|}
\hline \multicolumn{1}{|c|}{ Показатель } & БК $(\mathrm{n}=34)$ & ХНЯК $(\mathrm{n}=29)$ & $\mathrm{t}$ & $\mathrm{p}$ \\
\hline Диаметр артериолярной части капилляра, мкм & $10,02 \pm 0,27$ & $8,01 \pm 0,09$ & 6,61 & $<0,001$ \\
\hline Диаметр венулярной части капилляра, мкм & $14,99 \pm 0,23$ & $11,18 \pm 0,22$ & 11,85 & $<0,001$ \\
\hline
\end{tabular}

б

\begin{tabular}{|l|c|c|c|c|}
\hline \multicolumn{1}{|c|}{ Показатель } & БК $(\mathrm{n}=34)$ & $\begin{array}{c}\text { Контрольная группа } \\
(\mathrm{n}=17)\end{array}$ & $\mathrm{t}$ & $\mathrm{p}$ \\
\hline Диаметр артериолярной части капилляра, мКм & $10,02 \pm 0,27$ & $7,27 \pm 0,41$ & 5,74 & $<0,001$ \\
\hline Диаметр венулярной части капилляра, мкм & $14,99 \pm 0,23$ & $9,98 \pm 0,44$ & 11,15 & $<0,001$ \\
\hline
\end{tabular}

\begin{tabular}{|l|c|c|c|c|}
\hline \multicolumn{1}{|c|}{ Показатель } & $\begin{array}{c}\text { ХНЯК } \\
(\mathrm{n}=29)\end{array}$ & $\begin{array}{c}\text { Контрольная группа } \\
(\mathrm{n}=17)\end{array}$ & $\mathrm{t}$ & $\mathrm{p}$ \\
\hline Диаметр артериолярной части капилляра, мкм & $8,01 \pm 0,09$ & $7,27 \pm 0,41$ & 2,22 & $=0,031$ \\
\hline Диаметр венулярной части капилляра, мкм & $11,18 \pm 0,22$ & $9,98 \pm 0,44$ & 2,72 & $=0,009$ \\
\hline
\end{tabular}

У больных ХНЯК в микроциркуляторном русле отмечены нарушения, аналогичные тем, которые имеются при БК, однако степень их выраженности и частота меньше. Это в полной мере относится к деформации сосудов микроциркуляторного русла. Наиболее характерные микрогемодинамические изменения в СОПР в области щеки (расширенные венулы, нарушение венозного оттока) представлены на рис. 2 а. Отмечается замутненность капилляроскопического фона, свидетельствующая о тканевом отеке, также повышенная извитость микрососудов и дупликация капиллярных петель (рис. 2б).

На основании количественного анализа данных, полученных с помощью ККБ, выявлены достоверные отличия величины диаметра микрососудов больных ХВЗК и группы контроля (табл. 1). У больных БК и ХНЯК наблюдается увеличение диаметра артериолярной и венулярной частей капилляров по сравнению с контрольной группой, причем при БК изменения выражены больше, что служит подтверждением бо́льшей тяжести микрогемодинамических расстройств при БК.

Таким образом, полученные данные свидетельствуют о нарушениях микроциркуляции СОПР у больных ХВЗК. Это подтверждает результаты клинического обследования [16], на основании которого выявлена высокая частота развития хронического катарального стоматита у больных с БК и ХНЯК. Увеличение диаметра капилляров, выход из них эритроцитов, расширение микрососудов венулярного звена свидетельствует о застойной гиперемии, отеке, накоплении продуктов обмена, трофических и воспалительных расстройствах в тканях СОПР и раскрывает патогенетические механизмы, лежащие в основе высокой частоты встречаемости катарального стоматита у больных XВЗК. 


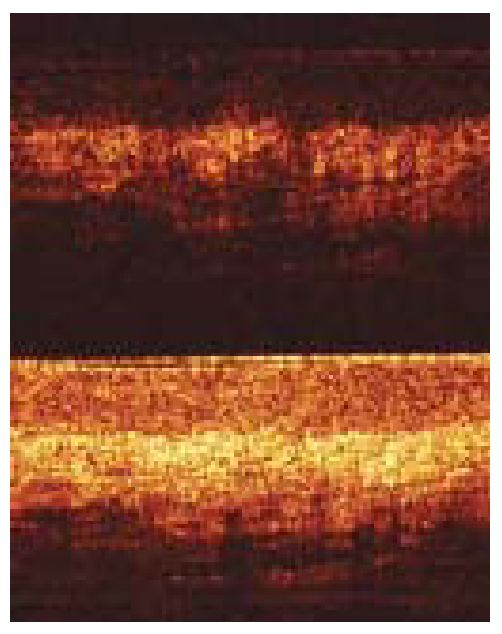

a

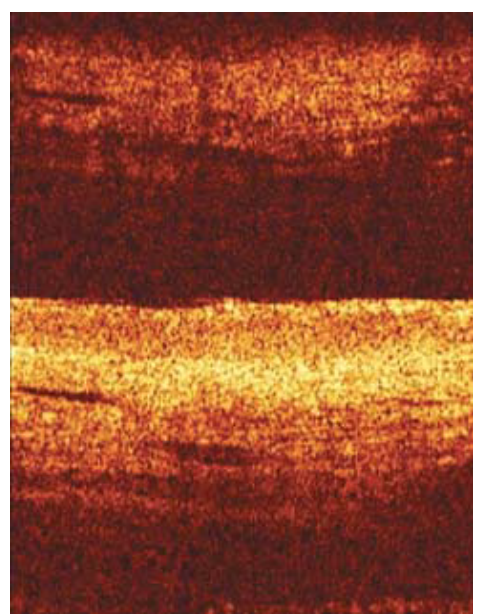

6

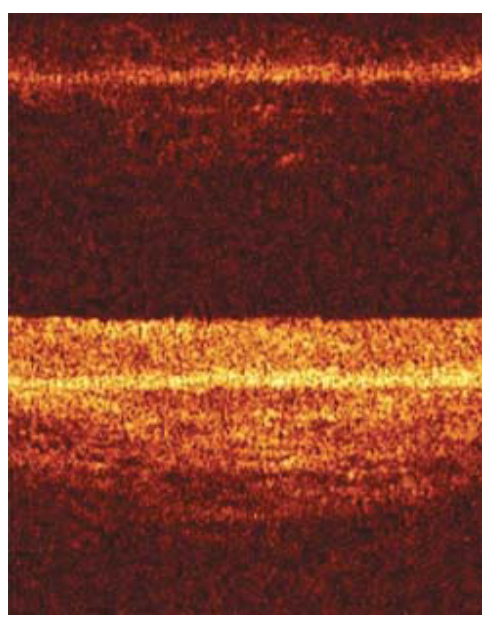

B

Рис. 3. КП ОКТ изображение слизистой оболочки щеки в прямой (внизу) и в ортогональной (сверху) поляризации: а - лиц контрольной группы; б - пациентов с БК; в - пациентов с ХНЯК.

Таблица 2

Показатели ИФД по КП ОКТ изображениям слизистой оболочки щеки лиц контрольной группы и больных ХВЗК

\begin{tabular}{|c|c|c|c|c|c|c|}
\hline БК $(\mathrm{n}=26)$ & ХНЯК $(\mathrm{n}=20)$ & Контрольная группа $(\mathrm{n}=20)$ & $\mathrm{t}$ & $\mathrm{p}$ & $\mathrm{U}$ & $\mathrm{p}$ \\
\hline $0,17 \pm 0,01$ & $0,13 \pm 0,01$ & $0,12 \pm 0,01$ & 2,33 & 0,03 & 17,00 & 0,02 \\
\hline
\end{tabular}

На КП ОКТ изображениях слизистой оболочки щеки лиц контрольной группы (рис. 3a) установлено слоистое строение, дифференцируются два горизонтально ориентированных слоя. Верхний слой имеет умеренную яркость и соответствует многослойному плоскому неороговевающему эпителию. Нижний слой неоднородный, высокой яркости, соответствует соединительнотканной строме. В нижнем слое наблюдаются области низкой яркости различной формы, соответствующие кровеносным сосудам, железам и их выводным протокам. Граница между верхним и нижними слоями резкая, четкая и непрерывная.

КП ОКТ изображения СОПР пациентов с БК (рис. 3б) отражают морфологические признаки воспаления слизистой оболочки. На изображениях в прямой поляризации признаки избыточного ороговения эпителия визуализируются как ослабление или потеря контраста эпителия и собственной пластинки слизистой, четкой слоистости не наблюдается. Во многих случаях визуализируются линейные негативные включения с контрастными границами, соответствующие накоплению в строме межтканевой жидкости. Верхний слой имеет неоднородную структуру, в ряде наблюдений его толщина увеличена по сравнению с контрольной группой. На ОКТ изображениях в ортогональной поляризации у больных БК обнаружена повышенная интенсивность сигнала от фиброзированного коллагена собственной пластины слизистой оболочки.

КП ОКТ изображения СОПР пациентов с ХНЯК характеризуются незначительным снижением контраста четко дифференцируемых оптических слоев и сохранением слоистой организации слизистой. Наблюдается слабая интенсивность сигнала от фиброзированного коллагена собственной пластины слизистой оболочки (рис. 3в).

Выявленная высокая интенсивность сигнала от фиброзированного коллагена собственной пластины слизистой у больных БК и более слабая интенсивность сигнала у больных ХНЯК подтверждается статистически значимым отличием показателя ИФД (табл. 2) при БК в сравнении с ХНЯК и контрольной группой $(\mathrm{p}<0,05)$.

Известно, что избыточный синтез коллагена и накопление коллагеновых волокон происходят в результате нарушений в системе синтеза/деградации коллагена. Такой дисбаланс приводит к фиброзу органа, то есть разрастанию волокнистой соединительной ткани, а в некоторых случаях хронического воспаления слизистых оболочек - к замене рыхлой волокнистой соединительной ткани на плотную. При репаративном фиброзе преобладает пролиферация фибробластов, индуцированная воспалением, а нарастание массы коллагена является следствием увеличения числа коллагенпродуцирующих клеток. Полагают, что воспалительная реакция околоэпителиальных 
тканей с дальнейшим фиброзом слизистой оболочки рта связана с усилением процессов структурирования коллагена путем повышения активности фермента лизилоксидазы [19]. Согласно литературным данным, склонность слизистой оболочки желудочно-кишечного тракта к фиброзу при болезни Крона можно считать доказанной [21, 25].

Таким образом, при оценке микроструктурных изменений слизистой оболочки полости рта на ОКТ изображениях в ортогональной поляризации у больных БК, при сравнении с контрольной группой и ХНЯК, обнаружена повышенная интенсивность сигнала от фиброзированного коллагена собственной пластинки слизистой оболочки, свидетельствующая об избыточном накоплении коллагена в соединительнотканной строме.

Определяемые увеличение диаметра артериолярной и венулярной частей капилляров, a также деформация микрососудов, замутненность и смазанность микрососудистого рисунка слизистой оболочки полости рта больных с хроническими воспалительными заболеваниями кишечника свидетельствуют о развитии ангиопатии, степень выраженности которой больше у пациентов с болезнью Крона по сравнению лицами, страдающими хроническим неспецифическим язвенным колитом.

\section{ЛИТЕРАТУРА}

1. Адлер Г. Болезнь Крона и язвенный колит. - М. : ГЭОТАР-Медиа, 2001. - 527 с.

2. Белоусова Е.А. Язвенный колит и болезнь Крона. Тверь : Триада, 2002. - 128 с.

3. Воробьев Г.И., Халиф И.Л. Неспецифические воспалительные заболевания кишечника. - М. : Миклош, 2008. - 400 с.

4. Григорьева Г.А., Мешалкина Н.Ю. О проблеме системных проявлений воспалительных заболеваний кишечника // Фарматека. - 2011. - № 15 (228). C. 14-49.

5. Златкина A.P. Белоусова Е.А. Внекишечные проявления болезни Крона // Рос. журн. Гастроэнтерол., гепатол., колопроктол. - 2001. - № 6. - С. 33-38.

6. Иорданишвили А.К., Бельских О.А., Тишков Д.С., Карев Ф.А., Музыкин М.И., Либих Д.А. Особенности функционирования слизистой оболочки полости рта и языка при хронических заболеваниях почек, кишечника и эндокринной патологии // Курский научно-практический вестник «Человек и его здоровье». - 2015. - № 4. - С. 31-40.

7. Иорданишвили А.К., Филиппова Е.В., Либих Д.А., Рыжак Г.А. Клинико-функциональное состояние слизистой оболочки полости рта и языка у людей старших возрастных групп // Институт стоматологии. - 2012. - № 4 (57). - С. 80-81.

8. Лебеденко И.Ю., Маев И.В., Муляр Е.А. Проявление неспецифического язвенного колита и болезни
Крона в полости рта // Российский стоматологический журнал. - 2002. - № 6. - С. 42-45.

9. Лепилин А.В., Осадчук М.А., Карабушина Я.Г. Патогенетические особенности воспалительных заболеваний пародонта при синдроме раздраженного кишечника // Успехи современного естествознания. - 2003. - № 8. - С. 99.

10. Маев И.В., Андреев Д.Н. Молекулярно-генетические механизмы развития болезни Крона // Молекулярная медицина. - 2014. - № 3. - С. 21-27.

11. Мялина Ю.Н., Козлова И.В., Лекарева Л.И. Системные проявления воспалительных заболеваний кишечника // Экспериментальная и клиническая гастроэнтерология. - 2014. - № 105 (5). - С. 71.

12. Осадчук М.А., Карабушина Я.Г., Гасанова Т.А. Хронический пародонтит при патологии толстой кишки: микробиологические параллели // Гастроэнтерология Санкт-Петербурга. - 2003. - № 2-3. C. 123.

13. Пихур О.Л., Робакидзе Н.С. Состояние твердых тканей зубов у больных с двигательными дисфункциями верхних отделов пищеварительного тракта // Институт стоматологии. - № 1. - 2007. C. 63-65.

14. Робакидзе Н.С., Барановский А.Ю., Щукина О.Б., Киселева Е.Б. Дифференциально-диагностические критерии болезни Крона и язвенного колита по состоянию слизистой оболочки рта // Институт стоматологии. - 2014. - № 3 (64). - С. 58-59.

15. Тытюк С.Ю., Иорданишвили А.К. Стоматологическое здоровье при хронических заболеваниях кишечника. - СПб : НордМедИздат, 2016. - 144 с.

16. Тытюк С.Ю., Пихур О.Л., Шулутко Б.И., Иорданишвили А.К., Карев Ф.А., Васильев А.В. Поражения органов и тканей полости рта при хронических воспалительных заболеваниях кишечника у взрослого человека // Курский научно-практический вестник «Человек и его здоровье». - 2015. - № 3. C. $49-55$.

17. Фомина Ю.В., Гладкова Н.Д., Масленникова А.В., Урутина М.Н., Раденска-Лоповок С.Г., Островский А.Д., Рабинович И.М., Фельдштейн Ф.И. Оптическая когерентная томография в стоматологии // Руководство по оптической когерентной томографии / Под ред. Гладковой Н.Д., Шаховой Н.M, Сергеева А.М. - М. : Физматлит, Мед. книга; 2007. - С. 203-246.

18. Цимбалистов А.В., Робакидзе Н.С., Тытюк С.Ю., Селютин А.В., Щукина О.Б., Сельков С.А. Клинико-иммунологические аспекты развития стоматологической патологии у больных с хроническими воспалительными заболеваниями кишечника // Научные ведомости Белгородского государственного университета. Серия: Медицина. Фармация. 2011. -T. 15, № 16-1 (111). - C. 114-118.

19. Ganganna K., Shetty P., Shroff S.E. Collagen in histologic stages of oral submucous fibrosis: A polarizing microscopic study // J. Oral Maxillofac. Pathol. - 2012. - Vol. 16, N 2. - P. 162-166.

20. Gibson J., Wray D., Bagg J. Oral staphylococcal mucositis: A new clinical entity in orofacial granulomatosis and Crohn's disease // Oral Surg. Oral 
Med. Oral Pathol. Oral Radiol. Endod. - 2000. Vol. 89, N 2. - P. 171-176.

21. Graham M.F., Diegelmann R.F., Elson C.O., Lindblad W.J., Gotschalk N., Gay S., Gay R. Collagen content and types in the intestinal strictures of Crohn's disease // Gastroenterology. - 1988. - Vol. 94. P. 257-265.

22. Logan R.M. Links between oral and gastrointestinal health // Curr. Opin. Support Palliat. Care. - 2010. Vol. 4, N 1. - P. 31-35.
23. Ojha J., Cohen D.M., Islam N.M., Stewart C.M., Katz J., Bhattacharyya I. Gingival involvement in Crohn's disease // J. Am. Dent. Assoc. - 2007. Vol. 138, № 12. - P. 574-1581.

24. Orosz M., Sonkodi I. Oral manifestations in Crohn's disease and dental management // Fogorv. Sz. 2004. - Vol. 97, N 3. - P. 113-117.

25. Stumpf M., Krones C.J., Klinge U., Rosch R., Junge $K$., Schumpelick $V$. Collagen in colon disease // Hernia. - 2006. - Vol. 10, N 6. - P. 498-501. 